OPEN ACCESS

Edited and reviewed by: Laura Airoldi,

University of Padova Chioggia

Hydrobiological Station, Italy

*Correspondence:

Paul Whomersley

paul.whomersley@cefas.co.uk

Specialty section

This article was submitted to

Marine Conservation and

Sustainability,

a section of the journal

Frontiers in Marine Science

Received: 24 January 2022 Accepted: 28 January 2022

Published: 24 February 2022

Citation:

Whomersley P, Bell J, Clingham E,

Collins MA, Feary DA, Stockill J,

Weber $S$, Yates $O$ and Bamford $K$ (2022) Editorial: Working Towards a Blue Future: Promoting Sustainability, Environmental Protection and Marine

Management: Examples from the UK

Government Blue Belt Programme and Current International Initiatives.

Front. Mar. Sci. 9:861632.

doi: 10.3389/fmars.2022.861632

\section{Editorial: Working Towards a Blue Future: Promoting Sustainability, Environmental Protection and Marine Management: Examples from the UK Government Blue Belt Programme and Current International Initiatives}

\author{
Paul Whomersley ${ }^{1 *}$, James Bell ${ }^{1}$, Elizabeth Clingham ${ }^{2}$, Martin A. Collins ${ }^{3}$, David A. Feary ${ }^{4}$, \\ Joanna Stockill ${ }^{5}$, Sam Weber ${ }^{6}$, Oliver Yates ${ }^{7}$ and Kylie Bamford ${ }^{8}$ \\ ${ }^{1}$ Centre for Environment, Fisheries and Aquaculture Science, Lowestoft, United Kingdom, ${ }^{2}$ St Helena Government, \\ Jamestown, Saint Helena, ${ }^{3}$ British Antarctic Survey, The Natural Environmental Research Council, Cambridge, \\ United Kingdom, ${ }^{4}$ Marine Resources Assessment Group (UK) Ltd., London, United Kingdom, ${ }^{5}$ Marine Management \\ Organisation, Newcastle upon Tyne, United Kingdom, ${ }^{6}$ Centre for Ecology and Conservation, University of Exeter, Penryn, \\ United Kingdom, ${ }^{7}$ Royal Society for the Protection of Birds, Sandy, United Kingdom, ${ }^{8}$ Foreign Commonwealth \& \\ Development Office, London, United Kingdom
}

Keywords: MPA (Marine Protected Area), policy, sustainable management, operational science, evidence informed decision making

Editorial on the Research Topic

Working Towards a Blue Future: Promoting Sustainability, Environmental Protection and Marine Management: Examples from the UK Government Blue Belt Programme and Current International Initiatives

\section{INTRODUCTION}

World-wide, the oceans are experiencing unprecedented rates of change associated with human activities. Overexploitation of species, degradation of habitats, biodiversity loss, a growing human population and changes in sea and land use are fundamentally altering the structure and function of marine ecosystems (Scheffer et al., 2001; Lubchenco et al., 2003; Jennings and Brander, 2010; Este et al., 2011; Díaz et al., 2019; Halpern et al., 2019). Effective and sustainable marine conservation and management strategies are urgently needed to halt the continued degradation of the world's oceanic and coastal environments (Devillers et al., 2015; Lubchenco and Grorud-Colvert, 2015; Ban et al., 2017; Roberts et al., 2017; Alvarez-Fenandez et al., 2020; Laffoley et al., 2020). International conventions and policies, most notably the Convention of Biological Diversity and the United Nations Sustainable Development Goal 14, called for at least $10 \%$ of the world's oceans to be protected by 2020 [Convention on Biological Diversity - Aichi biodiversity targets, 2010; United Nations Educational Scientific Cultural Organisation (UNESCO), 2017]. At present, an estimated $7.7 \%$ of the world's oceans are designated as Marine Protected Areas (MPAs) (The United Nations World Database of Protected Areas, 2021), with discussions to determine the type and extent of marine protection required post- 2020 currently underway (Campbell and Gray, 2019; Gownaris et al., 2019). 
Across the globe there are aspirations of reversing biodiversity loss through the protection of $30 \%$ of the world oceans by 2030 and a vision of living in harmony with nature by 2050. (The United Kingdom Government, 2018; Convention of Biological Diversity, 2019; The International Union for Conservation Nature, 2021) The declaration of the United Nations Decade of the Ocean Science for Sustainable Development encompassing 2021-2030 [United Nations Educational Scientific Cultural Organisation (UNESCO), 2017] has been developed to provide a common framework to unify and enable countries to undertake the ocean science necessary to sustainably manage oceans on a global scale and to ensure that connections between science, policy and societal needs are at the heart of the process (The United Nations decade of ocean science for sustainable development, 2020). One of the proposed mechanisms for achieving such ocean management is the designation of large-scale highly protected MPAs (Dudley et al., 2010; Leverington et al., 2010; Edgar et al., 2014; Watson et al., 2014). Highly protected MPAs can be a powerful conservation tool if appropriately managed from the point of designation (Lubchenco and Grorud-Colvert, 2015; Gownaris et al., 2019; Schratzberger et al., 2019; Alvarez-Fenandez et al., 2020). To effectively designate and sustainably manage such large areas of ocean and sea that can encompass a myriad of habitats and species, it is crucial that we understand the structure, function and resilience of the ecosystems therein. Such decisions involve many sources of evidence and require consideration of a complex interplay of social, political, legal, cultural, economic, and environmental concerns (Schratzberger et al., 2019). The wide range of competing interests means that, to be effective, decision-makers need to be presented with this evidence in a timely and accessible manner so it can be used to inform the development of future management and policy strategies.

\section{UK GOVERNMENT BLUE BELT PROGRAMME}

In 2016, the UK Government established its Blue Belt Programme $^{1}$, a broad initiative to develop and enhance marine management, protection and conservation across a number of its Overseas Territories. The Blue Belt Programme has focused on seven territories, including British Antarctic Territory, British Indian Ocean Territory, Pitcairn Islands, St Helena, Ascension Island and Tristan da Cunha, and South Georgia and the South Sandwich Islands.

This Programme has contributed to the delivery of the UK Government's commitment to provide protection of over four million $\mathrm{km}^{2}$ of marine environment across the UK Overseas Territories (UKOTs). This has been achieved through the provision of ongoing support for existing strategies of marine protection within British Indian Ocean Territory, South Georgia and the South Sandwich Islands and within British Antarctic Territory and through assisting in the development of new marine management and protection strategies within Pitcairn,

$\overline{{ }^{1} \text { https://www.gov.uk/government/publications/the-blue-belt-programme }}$
St Helena, Ascension Island and Tristan da Cunha Exclusive Economic Zones (EEZs).

High-level objectives of the Blue Belt Programme have been to:

1. Improve scientific understanding of the marine systems throughout the seven UKOTs;

2. Develop and implement evidence based, tailored marine management and protection strategies where these were not already developed and

3. Ensure that any management measures both ongoing and developed within the Blue Belt Programme are sustainable into the future.

\section{CONTENT}

The Blue Belt programme is delivered by the UKOTs in partnership with the Center for Environment, Fisheries and Aquaculture Science (Cefas) and the Marine Management Organization (MMO), in addition to collaborators and experts from around the world to generate additional knowledge to ensure that existing and newly developed marine protection strategies are well-designed, and that valuable marine areas and zones are effectively managed and monitored.

The geographic scope of this Frontiers in Marine Science Research Topic demonstrates the amount of work currently being undertaken in partnership with many UKOTs as they seek to protect and sustainably manage their marine estates. Included are studies encompassing UKOTs within the Blue Belt Programme (South Georgia and the South Sandwich Islands, Tristan da Cunha, St Helena, Ascension Island, Pitcairn Island and the British Indian Ocean Territory), as well as Monserrat. It brings together 22 papers that focus broadly on four key themes that demonstrate the importance of scientific data collection and how it has been utilized to deliver policy relevant evidence and advice for UKOT decision makers.

\section{Ecology and Status of Key Fisheries Species}

Sustainable management of fish and invertebrates requires detailed knowledge of the distribution, abundance and ecology of both target and non-target species. In the Tristan da Cunha EEZ, Campanella et al. use acoustics to detect and quantify major fish aggregations at seamounts, whilst Bell et al. and Heyworth et al. investigate the life-history traits and regional connectivity of the bluenose fish populations caught at those seamounts. In St Helena waters, Wright et al. apply both conventional and novel tagging methods to investigate patterns in the behavior of yellow-fin tuna, that will inform regional management of this economically valuable species. An economic study undertaken by Muench et al. to assess the viability of existing fisheries during the creation of a large scale MPA in the Ascension Island EEZ provides valuable insights into the potential socioeconomic impacts that MPA design and management practices could have if not considered during the design and designation phase of MPA planning and management. In addition, a study by Townhill et al. utilizes climate projection models under different 
emission scenarios to assess potential changes in the distribution of commercially important fish stocks in the vicinity of Ascension Island, St Helena and Tristan da Cunha under different climate scenarios, providing important information on how climate change may affect the livelihoods of small Island communities.

\section{Integrated and Adaptive Marine Management}

Robust monitoring of ocean health is vital for the development of an integrated and adaptive approach to marine management. This is often challenging in small communities with limited capacity and weak or non-existent environmental baselines. The two studies undertaken by Painting, Haigh, et al. and Painting, Nelson, et al. demonstrate the importance of monitoring and how baseline data can be used to develop assessment levels for coastal pollutants. McGoran et al. discuss the value of understanding potential sources of pollution, such as plastics and the extent and impacts of this pollution on marine systems, including the deep sea. Mynott et al. show how the collection of scientific data and evidence can be used to develop novel tools for conducting ecological risk assessments relating to anthropogenic activities in data poor environments. Duffy et al. discuss how long-term monitoring can inform the development of conservation objectives that result in the continued sustainable use of resources and minimize potential socio-economic impacts on local communities.

Stakeholder conflict is a common issue during the development and implementation of management strategies. Dosell et al. stress the importance of stakeholder engagement in data collection and as part of the decision-making process and highlight the importance of inclusivity in user conflict resolution and the development of evidence informed management and policy strategies. While Hardman et al. emphasize the importance of establishing multi-actor and multi-sector partnerships to aid stakeholder participation, offer technical expertise and to mobilize finance. Governance structures are essential to balance and trade-off competing objectives, resolve conflicts and develop integrated and adaptive management systems that enable managers and decision makers to coordinate planning and management across a range of sectors.

\section{Investigating Vulnerable Marine Ecosystems}

In order to conserve and protect vulnerable marine species, it is first necessary to understand how they interact with key habitats, where these habitats are located, and how susceptible they are to human activities. Downie et al. and Hogg et al. demonstrate that work to map the location of vulnerable habitats is essential during the MPA design and designation process to ensure that MPAs are placed in the correct location, therefore affording vulnerable marine ecosystems the level of protection they require. These articles also show the importance of baseline information during the management effectiveness assessment step of the MPA management cycle. Archer-Rand et al. and Bridges et al. illustrate how the modeling and mapping of tropical and cold water corals has provided information that has contributed to the designation of highly protected marine zones and the management of potentially damaging activities.
Dickens et al., Martin et al., Meeuwig et al., and Thompson et al. discuss how the mapping of oceanic features and the collection of sightings data of vulnerable marine species and land-based marine predators can be used to inform marine spatial protection and conservation strategies. Much of the research presented here has already directly informed management and policy decisions in the UKOTs, highlighting the value of targeted operational research delivered in a timely and accessible manner.

\section{Marine Protection and Enforcement}

The designation of large scale $\left(>100,000 \mathrm{~km}^{2}\right)$ MPAs is rapidly increasing on a global scale. How effective these large scale MPAs are at achieving their conservation objectives depends on the level of compliance with management measures. Collins et al. conclude that to improve compliance and therefore the potential for any management objectives to be met it is first necessary to understand both the social and economic drivers of non-compliance. Their article also considers how applicable the development and implementation of educational and incentive-based programmes are as an alternative to costly enforcement activities.

\section{SUMMARY}

The articles contained in this issue represent the outcomes of policy-driven, applied research, developed to fill the most critical knowledge and evidence gaps in the marine decisionmaking process. The outcomes of this work have already had demonstrable impact upon major policy decisions within the UKOTs, including the designation of large MPAs, the safeguarding of fisheries resources, the protection of vulnerable ecosystems, and the sustainable use of the marine environment. The articles highlight many of the challenges that have been overcome while working in remote locations with varying levels of infrastructure and governance. They demonstrate the importance of communication and what can be achieved through partnership working between Government agencies, non-governmental organizations, academic partners, and local stakeholders.

We, the authors, are proud to have worked alongside our UKOT colleagues to deliver co-created science that has been crucial to evidence-based decisions made during our journey toward sustainable ocean governance. Many of the UKOTs are remote communities that depend heavily on their marine environments and have limited means for economic diversification. Their willingness to consider their economic goals alongside those of global marine protection cannot be underestimated and they should be wholeheartedly congratulated on their commitment to building a sustainable future for our oceans.

\section{AUTHOR CONTRIBUTIONS}

All authors listed have made a substantial, direct, and intellectual contribution to the work and approved it for publication. 


\section{ACKNOWLEDGMENTS}

Thank you to all the authors that have contributed to this Research Topic and the editors and reviewers

\section{REFERENCES}

Alvarez-Fenandez, I., Freire, J., Naya, I., Fernandez, N., and SanchezCarnero, N. (2020). Failure in the design and implementation of management plans of Marine Protected Areas: an empirical analysis for the North-east Atlantic Ocean. Ocean Coast. Manag. 192, 105178. doi: 10.1016/j.ocecoaman.2020.105178

Ban, N. C., Davies, T. E., Aguilera, S. E., Brooks, C., Cox, M., Epstein, G., et al. (2017). Social and ecological effectiveness of large marine protected areas. Glob. Environ. Change 43, 82-91. doi: 10.1016/j.gloenvcha.2017.01.003

Campbell, L. M., and Gray, N. J. (2019). Area expansion versus effective and equitable management in international marine protected areas goals and targets. Marine Policy 100, 192-199. doi: 10.1016/j.marpol.2018.11.030

Convention of Biological Diversity. (2019). Post-2020 Global Biodiversity Framework Discussion Paper. CBD/POST2020/PREP/1/1. Post-2020 global biodiversity framework: discussion paper (cbd.int) (accessed January 2022).

Convention on Biological Diversity - Aichi biodiversity targets. (2010). Convention on Biological Diversity. Available online at: http://www.cbd.int/sp/ targets/ (accessed January 2022).

Devillers, R., Pressey, R. L., Grech, A., Kittenger, J. N., and Edgar, G. J. (2015). Reinventing residual reserves in the sea: are we favouring ease of establishment over need for protection? Aquat. Conserv. 25, 480-504. doi: 10.1002/aqc.2445

Díaz, S. J., Settele, E. S., Brondízio, H. T., Ngo, J., Agard, A., Arneth, P., et al. (2019). Pervasive human-driven decline of life on Earth points to the need for transformative change. Science 366:1-10. doi: 10.1126/science.aax3100

Dudley, N., Stolton, S., Belokurov, A., Kruegar, A. L., Lopoukhine, N., Mackinnon, K., et al. (2010). Natural Solutions: Protected Areas Helping People Cope with Climate Change. Washington, DC; New York, NY: IUCN WCPA, TNC, UNDP, WCS, The World Bank and WWF, Gland, Switzerland.

Edgar, G. J., Stuart-Smith, R. D., Wilis, T. J., Kininmonth, S., Baker, S. C., Banks, S., et al. (2014). Global conservation outcomes depend on marine protected areas with five key features. Nature 506, 216. doi: 10.1038/nature13022

Este, J. A., Terborgh, J., Brashares, J. S., Power, M. E., Berger, J., Bond, W. J., et al. (2011). Trophic downgrading of planet earth. Science 333, 301 doi: $10.1126 /$ science. 1205106

Gownaris, N. J., Pikitch, E. K., Santora, C. M., and Davis, J. (2019). Mapping consensus on global marine priority regions. Front. Mar. Sci. 6, 650. doi: 10.3389/fmars.2019.00650

Halpern, B. S., Frazier, M., Afflerbach, J., Lowndes, J. S., Micheli, F., O’Hara, C., et al. (2019). Recent pace of change in human impact on the world's ocean. Sci. Rep. 9, 11609. doi: 10.1038/s41598-019-47201-9

Jennings, S., and Brander, K. (2010). Predicting the effects of climate change on marine communities and the consequences for fisheries. J. Mar. Syst. 79, 418-426. doi: 10.1016/j.jmarsys.2008.12.016

Laffoley, D., Baxter, J. M., Amon, D. J., Currie, D. E. J., Downs, C. A., HallSpencer, J. M., et al. (2020) Eight urgent, fundamental and simultaneous steps needed to restore ocean health, and the consequences for humanity and the planet of inaction or delay. Aquat. Conserv.: Mar. Freshw. Ecosyst. 30, 194-208. doi: $10.1002 /$ aqc. 3182

Leverington, F., Costa, K. L., Pavese, H., Lisle, H., and Hockings, M. (2010). A global analysis of protected area management effectiveness. Environ. Manag. 46, 685-698. doi: 10.1007/s00267-010-9564-5

Lubchenco, J., and Grorud-Colvert, K. (2015). Making waves: the science and politics of ocean protection. Science 6259, 382-383. doi: $10.1126 /$ science.aad 5443 who have dedicated their time to ensuring the high quality of contributions. Thank you also to the UK Government Blue Belt Programme for funding this initiative.
Lubchenco, J., Palumbi, S. R., Gaines, S. D., and Andelman, S. (2003). Plugging a hole in the ocean: the emerging science of marine reserves. Ecol. Applic. 13(Suppl.), 3-7. doi: 10.1890/1051-0761(2003)0130003:PAHITO2.0.CO;2

Roberts, C. M., O’Leary, B. C., McCauley, D. J., Cury, P. M., Duarte, C. M., Lubchenco, J., et al. (2017). Marine reserves can mitigate and promote adaptation to climate change. Proc. Natl. Acad. Sci. U. S. A. 114, 6167-75. doi: 10.1073/pnas.170126 2114

Scheffer, M., Carpenter, S., Foley, J. A., Folke, C., and Walker, B. (2001). Catastrophic shifts in ecosystems. Nature 413, 591-596. doi: 10.1038/3509 8000

Schratzberger, M., Neville, S., Painting, S., Weston, K., and Paltriguera, L. (2019). Ecological and socio-ecological effects of highly protected marine areas (HPMAs) in temperate waters. Front. Mar. Sci. 6, 749. doi: 10.3389/fmars.2019.00749

The International Union for Conservation of Nature. (2021). IUCN Position on Updated Zero Draft Post 2020 Global Biodiversity Framework. Available online at: https://www.iucn.org/sites/dev/files/iucn_position_on_the_updated_zero_ draft_of_the_post-2020_global_biodiversity_framework_-_april_2021.pdf

The United Kingdom Government. (2018). Press release - Calls for 30 per cent of world's oceans to be protected by 2030. Gove calls for 30 per cent of world's oceans to be protected by 2030 - GOV.UK (www.gov.uk) (accessed January 2022).

The United Nations decade of ocean science for sustainable development (2020). Intergovernmental Oceanographic Commission (IOC) Brochure 20204 (IOC/BRO/2020/4).

The United Nations World Database of Protected Areas. (2021). Explore the World's Protected Areas (protectedplanet.net) (accessed January 2022).

United Nations Educational Scientific and Cultural Organisation (UNESCO). (2017). United Nations announces Decade of Ocean Science (2021-2030) (unesco.org) (accessed January 2022).

Watson, J. E. M., Dudley, N., Segan, D. B., and Hockings, M. (2014). The performance and potential of protected areas. Nature 515, 67-73. doi: $10.1038 /$ nature 13947

Conflict of Interest: DF was employed by the company MRAG Ltd.

The remaining authors declare that the research was conducted in the absence of any commercial or financial relationships that could be construed as a potential conflict of interest.

Publisher's Note: All claims expressed in this article are solely those of the authors and do not necessarily represent those of their affiliated organizations, or those of the publisher, the editors and the reviewers. Any product that may be evaluated in this article, or claim that may be made by its manufacturer, is not guaranteed or endorsed by the publisher.

Copyright (c) 2022 Whomersley, Bell, Clingham, Collins, Feary, Stockill, Weber, Yates and Bamford. This is an open-access article distributed under the terms of the Creative Commons Attribution License (CC BY). The use, distribution or reproduction in other forums is permitted, provided the original author(s) and the copyright owner(s) are credited and that the original publication in this journal is cited, in accordance with accepted academic practice. No use, distribution or reproduction is permitted which does not comply with these terms. 